\title{
REFERENCES
}

Boyle, J. D., Pearce, M. L., Guze, L. B. (1961): 'Purulent Pericarditis'. Medicine (Baltimore). 40, i 19.

FLOREY, M. E. (1952): in 'The Clinical Application on the Antibiotics, Vol. I. Penicillin', p. 417. London: Oxford University Press.

Foley, M. M., Probert, W. R., SeAL, R. M. E. (1956): 'False Aneurysm of Ascending 'Thoracic Aorta Complicating Tuberculous Pericarditis'. Tubercle (Edinb.), 37, 183.

McKusick, V. A., HarveY, A. McG. (1955): 'Diseases of the Pericardium'. Advanc. intern. med., 7, 157.

Maloney, G. E.G. (1955): 'Excision of an Aneurysm of the Right Subclavian Artery'. Brit. Y. Surg., $43,94$.

RoB, C., NGU, V. (1960): 'Mykotische Aneurysmen unklarer Atiologie'. Dtsch. med. Wschr., 85, i 157.

Smith, G., Hutchison, H. E. (1957): 'Lymph Borne Infection and Aneurysm Formation'. Surg. Gynec. Obstet., I04, 722.

\section{PORTAL HYPERTENSION IN THE ABSENCE OF CIRRHOSIS OR OBSTRUCTION IN THE PORTAL VEIN}

\author{
Leslie Turnberg, M.B., Ch.B., M.R.C.P. \\ Medical Registrar, University College Hospital, London, W.C.r.
}

PORTAL hypertension in man is usually associated with obstruction to blood flow through the portal vein system either within the liver, as in cirrhosis, or in the vein itself, as may follow neonatal portal thrombo-phlebitis. According to the site of obstruction, portal hypertension is described as of intra- or extra-hepatic origin. Increased resistance to flow through the hepatic veins, as in the BuddChiari syndrome, is also associated with a raised portal pressure, and this form has been described as of supra-hepatic origin. Recently a more elegant distinction has been made between portal hypertension of pre- and post-sinusoidal origin, according to whether there is a normal or raised wedged hepatic venous pressure respectively (Taylor and Myers, I956), cirrhosis commonly giving rise to the post-sinusoidal type and occlusion of the portal vein a pre-sinusoidal type.

There is a group of patients, however, who have portal hypertension with a well developed collateral circulation in the absence of any organic obstruction to flow through the portal vein or its intrahepatic branches. The following case is an example of this unusual and interesting condition.

\section{Case Report}

J. G., a 7-year-old schoolboy, presented at the Central Middlesex Hospital on 31.12.62, with a small hæmatemesis. His past history included measles and mumps but was otherwise unremarkable. He was the middle child in a family of three, born in England of Irish parents. His sisters, aged 12 years and 3 years, and both his parents were well although his mother was said to have mild asthma. His birth was normal, he was not jaundiced in the neonatal period and there was nothing that could be taken for a history of umbilical sepsis with portal vein thrombosis. There was no past history of hepatitis and he had not been taking aspirin or other drugs prior to his hæmorrhage. He had, according to his parents, been quite well until the day of admission when he vomited three or four clots of bright red blood. He was noted to have a palpable spleen, $\mathrm{Hb} .28 \%$, w.b.c. $3,200 /$ cu.mm., platelets $40,000 /$ cu.mm. He was given a transfusion of whole blood and allowed home to await further investigation.

During the following three weeks he remained rather unwell although he complained of no specific symptoms. On 21.1.63 he was admitted to the Whittington Hospital under the care of Dr. S. Yudkin, for investigation, and was found to be clinically anæmic, to have two bruises on his leg and to have an enlarged spleen palpable three finger-breadths below the costal margin. His liver was just palpable but not enlarged, and there were no bruits audible over the liver or spleen.

Investigations: $\mathrm{Hb} .45 \%$ and $40 \%$, w.b.c. 2,500 and $2,000 /$ cu.mm. ( $85 \%$ neutrophils), platelets 100,000 and $86,000 /$ cu.mm. Sternal marrow biopsy showed a hyper-cellular normoblastic marrow with increase in the red cell precursors. All biochemical tests of liver function were normal and were as follows: S. Bilirubin $0.65 \mathrm{mg}$./ $100 \mathrm{ml}$., S. alkaline phosphatase $12 \mathrm{~K}$.A. units, S. proteins $6.7 \mathrm{gm}$. $/ 100 \mathrm{ml}$., S. albumin 4.I and globulin $2.6 \mathrm{gm}$./100 ml., with a normal electrophoretic strip. Thymol turbidity 2 and zinc sulphate turbidity 6 . Prothrombin time 17 seconds (control 15 seconds). Urine urobilinogen normal. A percutaneous liver biopsy was taken with a Menghini needle and was quite normal.

A diagnosis of primary hypersplenism was considered and he was transferred to Dr. T. A. J. Prankerd's care at University College Hospital for further investigation of red cell survival. ${ }^{51} \mathrm{Cr}$. labelled red cell survival $(\mathrm{Dr}$. $P$. Toghill) was $T_{1} 20$ days showing slightly decreased survival compared with a normal of 24-26 days. At one stage during the observations there was a rather more rapid fall in blood activity suggesting occult gastrointestinal bleeding. Counting over the spleen showed no pooling or evidence of excessive splenic destruction of red cells. Fæcal occult blood testing was strongly positive on two occasions, moderately positive on three 


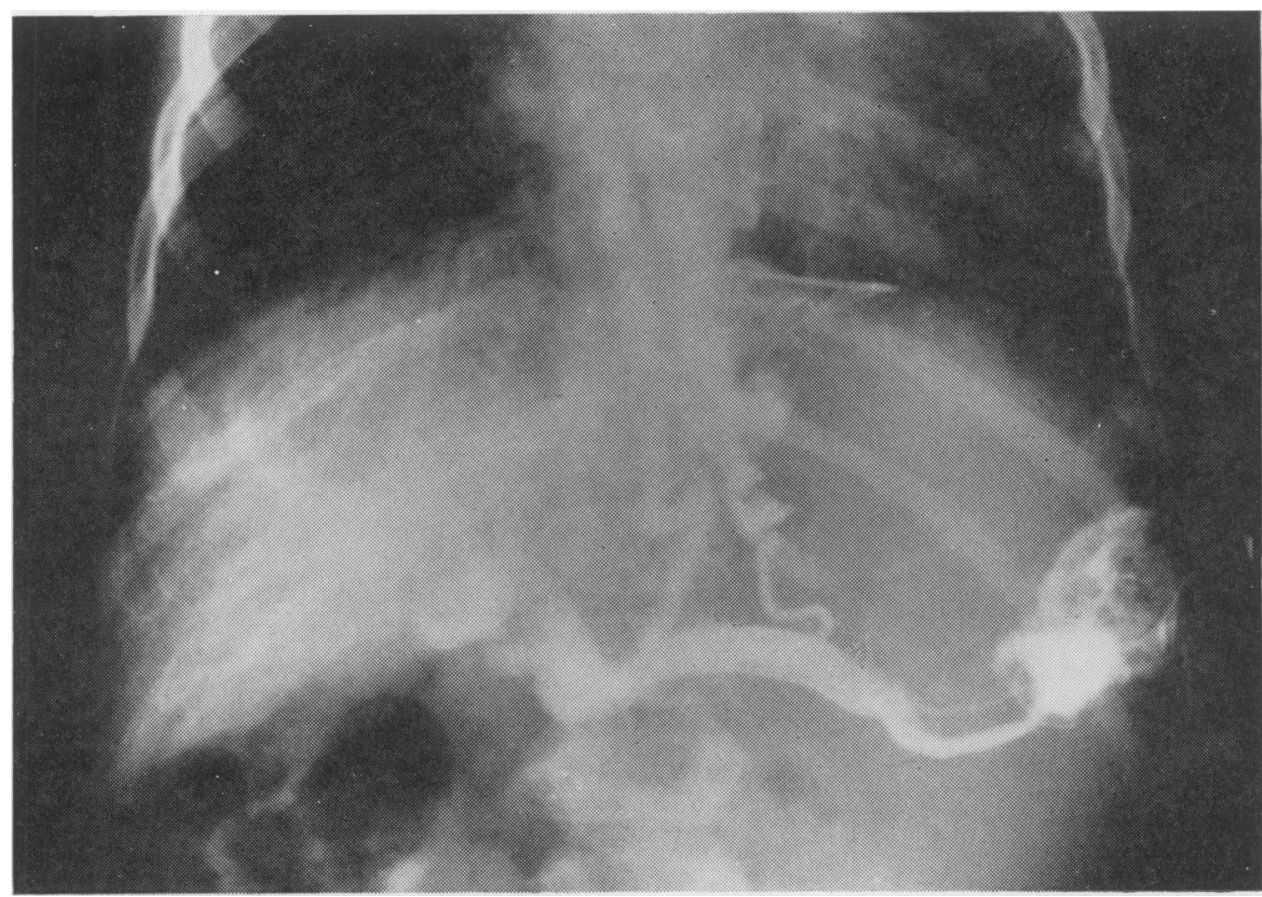

Fig. 1.-Porta-venogram.

and negative on one, and the serum iron was low at $25 \mathrm{\mu gm}$. $/ 100 \mathrm{ml}$.

Portal hypertension with bleeding varices was reconsidered, with the normal liver biopsy suggesting extra-hepatic obstruction. Barium swallow and meal was quite normal and failed to show any evidence of varices. A percutaneous trans-splenic porta-venogram was then performed (Dr. D. Edwards) (Fig. I). Intrasplenic pressure was more than $44 \mathrm{~cm}$. saline. The portal vein outlined well and was large, dilated and tortuous. The intra-hepatic radicles filled without delay and appeared quite normal, and the hepatogram showed a normal liver size and architecture. There were large dilated varices demonstrated at the lower end of the œsophagus and upper end of the stomach.

In view of this finding it was decided to advise a portacaval shunt to try to relieve the portal hypertension and reduce the likelihood of further hæmorrhage.

Operation 29.3.63 (Miss D. Nightingale). The portal vein was found to be large, dilated and thin-walled. It branched rather low down, there was a large varix on it just proximal to the porta hepatis, and there were many dilated collateral vessels on the stomach wall. The liver appeared quite normal, and a wedge from the anterior surface was taken for biopsy (Fig. 2). An endto-side portal-caval anastomosis was then performed. The post-operative course was fairly straightforward although he did have one small hæmatemesis four days post-op., an hour after he was given a soluble aspirin for a headache. He remained well after this and was discharged on the 23rd post-op. day. His spleen at discharge had reduced in size from $5 \mathrm{~cm}$, to $3 \mathrm{~cm}$. below the costal margin. Three months post-op. he remained well and he had maintained his hæmoglobin at $80 \%$ although his spleen remained palpable.

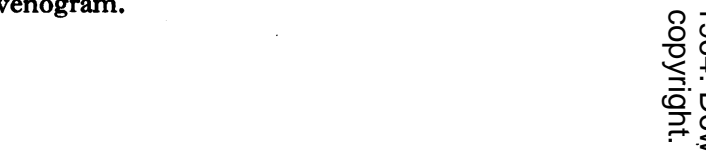

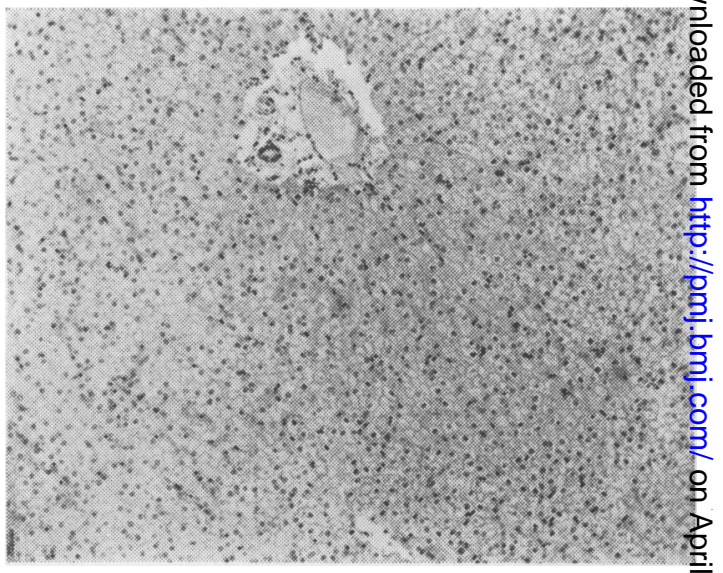

Fig. 2.-Liver biopsy showing normal histology.

\section{Discussion}

In I 894 Banti described a syndrome which in cluded splenomegaly, portal hypertension and anæmia. It was thought that the liver was initiall normal and that cirrhosis only developed later, bufe it soon became clear that in most cases of Banti' of syndrome cirrhosis was the prime lesion and the cause of the portal hypertension. Portal hypere tension occurring in patients without cirrhosis was assumed to be due to occlusion of the extra-hepatie 
portion of the portal vein, obstruction to flow appearing to be the most important factor (Rousselot, 1940). However, in several of the early series of cases of portal hypertension there was a proportion in whom it was not possible to demonstrate the site of the presumed block (Osler, 1900; Rousselot, 1940; Whipple, 1945; Pemberton and Kiernon, 1945). That increased resistance to flow is of importance in the development of portal hypertension is evidenced by the common association of the two, but it is a source of dissatisfaction that there is little correlation between the degree of obstruction and the level of portal pressure. Milnes Walker (1959) for instance, mentions cases with very minimal signs of cirrhosis who have considerable portal hypertension. More recently Polish, Christie, Cohen and Sullivan (1962) described the case of a 23-year-old male with portal hypertension without cirrhosis or portal vein obstruction, and Tisdale, Klatskin and Glenn (1959) discussed four cases with an age range of 1o to 72 years. Valdoni (1963) has noted that portal hypertension in the absence of cirrhosis or portal vein block occurs not uncommonly in the Mediterranean area.

Adequate porta-venography has virtually excluded such lesions as short strictures of the portal vein in the porta hepatis as possible causes of the portal hypertension in these cases. The suggestion that increased tone in the portal vein or its intrahepatic radicles may give rise to portal hypertension in the absence of organic obstruction (Walker, 1958) has little evidence to support it.

Apart from the resistance of the portal bed, the other main factor influencing portal pressure is the rate of blood flow through that bed (Bradley, r 963) and it is reasonable to suggest that an increased rate of flow might be responsible for the portal hypertension noted in those cases without obstruction. This increased flow rate may arise in the vascular bed of the liver, spleen or intestinal tract, and shunting of blood through multiple arterio-venous communications seems the most likely mechanism (Womack and Peters, 1957).

A case of portal hypertension due to large arteriovenous shunts in the spleen and cured by splenectomy has been recorded (Murray, Thal and Greenspan, 1960), and similarly a case due to a single large aneurysm between the hepatic artery and portal vein has also been reported (Madding, Smith and Hershberger, 1954).

While there is evidence for the presence of multiple small shunts between the hepatic artery and portal vein in cirrhotic livers (Popper, Elias and Petty, 1952) it is not at all certain that they exist in normal livers or that they have much influence on portal pressure.

There is, however, good evidence that the rate of blood flow through the splanchnic circulation in the spleen and alimentary tract has a considerable influence on portal pressure (Bradley, 1963), and the evidence in favour of an increased flow-rate causing portal hypertension is admirably presented by Peters and Womack (196r). They noted that the blood in œsophageal varices is highly oxygenated, suggesting the shunting of arterial blood into these veins, and such shunts have been demonstrated histologically in the spleen (Ham, 1957) and submucosa of the stomach (Barclay and Bentley, 1949) and bowel (Boulter and Parks, 1960). They suggested that these shunts are under the control of a humoral substance liberated from the liver under different conditions. With evidence both that splanchnic blood flow is a major determinant of portal pressure and of a mechanism whereby changes in that blood flow can be made, it would be reasonable to suggest that in patients with portal hypertension, increase in splanchnic blood flow may be an important contributory factor.

If the normal portal pressure is taken as up to $25 \mathrm{~cm}$. saline, then the patient presented here was certainly hypertensive with an intra-splenic pressure of above $44 \mathrm{~cm}$. saline, intra-splenic pressures usually corresponding fairly closely to the portal pressure (Atkinson and Sherlock, 1954). He had a perfectly normal liver both macro- and microscopically, there was no evidence of hepatic vein occlusion and there was nothing that could be taken for an old thrombosed portal vein or cavernous transformation. There were no definite signs of an isolated arterio-venous fistula in the spleen, and the porta-venogram excluded any local strictures of the portal vein in the porta hepatis. The rtiology of this patient's portal hypertension is thus obscure when purely obstructive factors are considered, but an increased splanchnic flow offers a rather more acceptable explanation. It is difficult to obtain proof of an increased volume-flow through the splenic or mesenteric veins by direct estimations, and unfortunately these necessary measurements were not obtained in this patient. It would be important, however, to try to secure this information, not only in similar cases but in cirrhotic patients too, possibly by means of the square-wave electromagnetic flow meter utilized for similar purposes in animals by Stewart, Stephens, Leslie, Portin and Schenk (1958).

\section{Summary}

The case of a 7-year-old boy with portal hypertension occurring in the absence of cirrhosis or obvious block in the portal vein is presented.

The ætiology of the portal hypertension is obscure, but it is suggested that increased blood flow through small arterio-venous shunts in the wall of the alimentary tract or in the spleen may be responsible.

Further investigation which might give information on the atiology of portal hypertension in patients with cirrhosis as well as in those without obstruction is suggested.

My grateful thanks are due to Dr. T. A. J. Prankerd for his kind encouragement and for permission to report this case. I would also like to record my debt to Dr. J. F. Stokes for the invaluable advice and guidance he provided in the preparation of this paper. 


\section{REFERENCES}

Atkinson, M. and Sherlock, S. (1954): Intra-splenic Pressure as Index of Portal Venous Pressure. Lancet i, I3 3 .

BanTI, G. (1894): Splenomegaly with Cirrhosis of the Liver. Med. Classics, (1937). I, 907.

BARCLAY, A. E., and BENTLEY, F. H. (I949): The Vascularization of the Human Stomach. A preliminary note on the

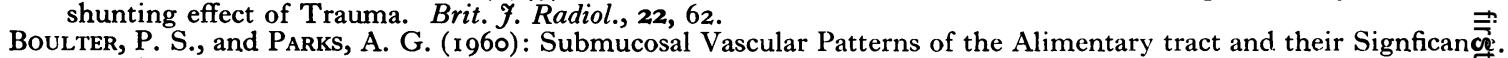
Brit. F. Surg., 47, 546 .

Bradley, S. E. (1963): The Circulation and the Liver. Gastroenterology, 44, 403.

HAM, A. W. (1957): Histology 3 rd Ed., p. 379. London: Pitman. med. Ass., 156, 593.

Murray, M. J., Thal, A. P., and GreensPan, R. (1960): Splenic Arteriovenous Fistulas as a Cause of Portal Hypertę⿵sion. Amer. F. Med., 29, 849.

Osler, W. (1900): On Splenic Anæmia. Amer. F. med. Sci., 119, 54.

Pemberton, J. de J., and Kiernon, P. (1945): Surgery of the Spleen. Surg. Clin. N. Amer., 25, 880.

Peters, R. M., and Womack, N. A. (196I): Surgery of Vascular distortions in Cirrhosis of the Liver. Ann. Survi, I54, 432 .

Polish, E., Christie, J., Cohfn, C. A., and Sullivan, B. (1962): Idiopathic Presinusoidal Portal Hypertension. A intern. Med., 56, 624 .

Popper, H., Elias, H., and Petry, D. E. (1952): Vascular Pattern of the Cirrhotic Liver. Amer. F. Clin. Path., 22, 7 录.

Rousselot, L. M. (1940): The Late phase of Congestive Splenomegaly (Banti's syndrome) with Hæmatemesis bet without Cirrhosis of the Liver. Surgery, 8,34 .

Stewart, J. D., Stephens, J. G., Leslie, M. B., Portin, B. A., and Schenk, W. G. (1958): Portal Hæmodynamâgs Under Varying Experimental Conditions. Ann. Surg., 147, 868.

TAYLOR, W. J., and MYERS, J. D. (1956): Occlusive Hepatic Venous Catheterization in the Study of the Normal Live Cirrhosis of the Liver and Noncirrhotic Portal Hypertension. Circulation, 13, 368.

Tisdale, W. A., Klatskin, G., and GlenN, W. W. L. (1959): Portal Hypertension and Bleeding Esophageal Varices, Their occurrence in the Absence of Both Intrahepatic and Extrahepatic Obstruction of the Portal Vein. Netw Engl. F. Med., 261, 209.

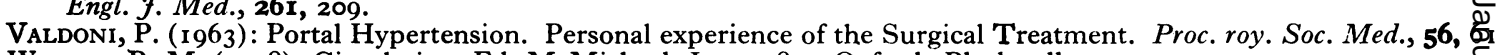

WALKER, R. M. (1958): Circulation, Ed. McMichael, J., p. 382. Oxford: Blackwell.

(1959): The Pathology and Management of Portal Hypertension. p. 25. London: Edward Arnold.

Whipple, A. O. (1945): The Problem of Portal Hypertension in relation to the Hepato-splenopathies.

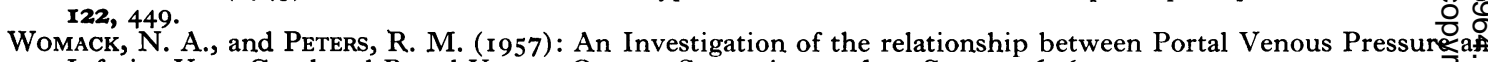
Inferior Vena Caval and Portal Venous Oxygen Saturations. Ann. Surg., 146, $69 \mathrm{I}$. 